\title{
Studying Vulnerability in Technological Cultures
}

Citation for published version (APA):

Bijker, W. E., Hommels, A. M., \& Mesman, J. (2014). Studying Vulnerability in Technological Cultures. In A. Hommels, J. Mesman, \& W. E. Bijker (Eds.), Vulnerability in Technological Cultures. New Directions in Research and Governance (pp. 1-26). MIT Press. https://doi.org/10.7551/mitpress/9209.003.0002

Document status and date:

Published: 01/01/2014

DOI:

10.7551/mitpress/9209.003.0002

Document Version:

Publisher's PDF, also known as Version of record

Document license:

Taverne

Please check the document version of this publication:

- A submitted manuscript is the version of the article upon submission and before peer-review. There can be important differences between the submitted version and the official published version of record.

People interested in the research are advised to contact the author for the final version of the publication, or visit the DOI to the publisher's website.

- The final author version and the galley proof are versions of the publication after peer review.

- The final published version features the final layout of the paper including the volume, issue and page numbers.

Link to publication

\footnotetext{
General rights Owners
rights.

- You may freely distribute the URL identifying the publication in the public portal. please follow below link for the End User Agreement:

www.umlib.nl/taverne-license

Take down policy

If you believe that this document breaches copyright please contact us at:

repository@maastrichtuniversity.nl

providing details and we will investigate your claim.
}

Copyright and moral rights for the publications made accessible in the public portal are retained by the authors and/or other copyright owners and it is a condition of accessing publications that users recognise and abide by the legal requirements associated with these

- Users may download and print one copy of any publication from the public portal for the purpose of private study or research.

- You may not further distribute the material or use it for any profit-making activity or commercial gain

If the publication is distributed under the terms of Article $25 \mathrm{fa}$ of the Dutch Copyright Act, indicated by the "Taverne" license above, 


\section{Studying Vulnerability in Technological Cultures}

Wiebe Bijker, Anique Hommels, and Jessica Mesman

Vulnerability in technological cultures is all around us. ${ }^{1}$ Such vulnerability may be caused by the techno-scientific character of our societies, as when a power failure stops all electricity-driven activities. Or it may result from natural events, such as hurricanes, but then the vulnerability is often shaped by technological circumstances, such as unexpectedly breaking levees. Societies also seek to defend against vulnerabilities by using science and technology, as in the case of high-tech storm surge barriers or innovative forms of non-pesticide crop management. The boundary between the technical, social, and natural can be fuzzy, though: for instance, was the breakdown in international business in the spring of 2010 due to the eruption of the Icelandic volcano Eyjafjallajökull which caused ash to cover large areas of northern Europe, the high-tech character of air transportation, or our culture of global mobility?

Vulnerabilities are not usually given in an unambiguous way. Depending on your perspective, you may deem the neonatology ward of a hospital a strategic research site to study vulnerability (because so many babies there hover on the edge between life and death) or a very safe place (considering that there is a low level of failures given the socio-technical complexities of the situation).

Vulnerability, finally, is not only or purely negative. A certain degree of vulnerability is necessary to create space for learning and adaptation in a society. Vulnerability, in this sense, is equivalent to openness and flexibility. Once properly addressed, such vulnerability with accompanying coping mechanisms may yield a more flexible and resilient society than one that tries to avoid all vulnerabilities. People living in cities that are vulnerable to frequent power failures have developed flexible ways of coping with such electricity shutdowns. This means that such cities are probably better able to cope with an even bigger blackout, while a less vulnerable city 
with less experience in dealing with small shutdowns might be completely paralyzed by that same big blackout.

This is the vulnerability that we seek to investigate in this volume: heterogeneous and varied by being related to science and technology, by being context-dependent, and by having not necessarily only negative connotations. Why study vulnerability at all? The primary goal of this volume is to make a bold argument that scholars should use vulnerability as a frame to understand our world and contribute to a better world, rather than losing themselves in detailed technical risk analyses and rhetoric. (As we shall argue below, we do not mean to criticize risk studies, but to propose a more encompassing and compassionate frame for these questions.) We want to call attention to issues of justice and livelihood in a globalizing world. Studying the relations between science, technology, and society (which we call "STS studies") has yielded a broad range of empirical and theoretical insights. This now offers a solid base to address "big" questions of justice, peace, and democracy. We argue, and the authors in this volume demonstrate, that asking questions about vulnerability is a promising way to address such "big" issues in technological cultures.

Today's modern societies are thoroughly scientific and technological. They rely heavily on scientific advice, scientific-technical standards, and technological systems. Science and technology are not neutral: they shape our activities and our sensemaking. When a new technique or instrument is adopted in medical practice, it transforms not only what doctors and their patients do, but also the way they think; this may also imply shifts in the meaning of health, illness, and medical care. The tank irrigation systems in South India are shaped by the social and cultural relations between Hindu and Muslim farmers (Shah, 2003). And coastal defense (we mean dunes, dikes, and levees) in the Netherlands and the United States mirror the differences in risk culture in both countries (Bijker, 2007). If technologies are socially shaped, societies are technologically built (Bijker \& Law, 1992).

New, science-based technologies such as the Internet, genetic engineering, nanotechnologies, and new forms of sustainable energy production create numerous opportunities for modern societies. But at the same time, none of these novel technologies is without risks. Citizens, governments, universities, and businesses face challenges when trying to take advantage of the seemingly infinite opportunities that scientific and technological developments offer, and there may be unintended consequences, with disastrous effects on society. The Challenger space shuttle explosion, the Chernobyl nuclear accident, the Bhopal chemical disaster, and the Exxon
Valdez oil spill in the 1980s reminded us that large-scale systems are vulnerable to human error and technical malfunctioning, with far-reaching consequences. Accidents, as Charles Perrow (1984/1999) argued, are "normal" in large, complex, and tightly knit technological systems. Modern societies, as Ulrich Beck $(1986,1992)$ diagnosed, are "risk societies." Science and technology not only help to tame risk and vulnerability; they also create new risks, vulnerabilities, and possibilities for accidents. Once we have large technological systems, accidents are inevitable; because we live in modern scientific and high-tech societies, risks are inevitable. In other words, scientific and technological developments do not only support and strengthen societies; they also make societies vulnerable at the same time. Such vulnerability is an inevitable characteristic of today's technological cultures.

In this book, we will explore vulnerabilities in technological cultures. Our focus on vulnerability is not pitted against the existing work in risk studies. The authors in this volume have actively contributed to and are drawing on research in risk studies and related fields. As we will argue in this introduction, however, we hope that an agenda in terms of vulnerabilities will allow for a novel and broader understanding of key questions related to the risks and benefits of science and technology in modern societies. Broadening the analysis from risk to vulnerability, we argue, will draw attention to issues of justice, solidarity, and livelihood. It will also help us to include comparative research on societies in the global north and south.

This book engages with a number of crucial issues of the role of vulnerability in current societies. First of all, we focus on the issue what vulnerability can mean and how it affects cultures and societies. Both Bangladesh and the Netherlands experience a risk of flooding. Yet, evidently, the people in the Netherlands are vulnerable in a different way than the people in Bangladesh, and they both have different ways of coping: differences in geography, climate, and social and technical infrastructures make for a very different impact of an eventual flooding disaster. Different value systems, community relations, and knowledge and technology systems induce different defense strategies. Do societies in the global south and north have different vulnerabilities and different coping strategies? Showing the multiplicity of vulnerability-the idea that different actors give different meanings to it and that vulnerability is the outcome of specific circumstances-is one of the key arguments of this book.

Second, this book concerns the conceptual frameworks for empirical description and theoretical analysis of vulnerability. These frameworks elucidate the complex and interwoven dimensions of the vulnerability issue. 
A study of vulnerability, therefore, requires insight in the analytical and political potential of such concepts. We aim to explore theoretical concepts that illustrate the ambiguity, context-dependency, and constructed character of vulnerability. An investigation of concepts such as bricolage, dissent, and imagination reveals that deviation from rules, standards, and protocols will not lead automatically to more vulnerability in all cases. Rules and practices that produce resilience in one context may result in vulnerability
in another.

Third, this book deals with the governance implications of living in vulnerable technological cultures, discussing, for instance, how the governance of vulnerabilities can be organized. Which practices, which politics, and which ethics are needed to cope with vulnerability in technological cultures? Discussing national and international risk policies, risk regulation in the chemical industry, and health prevention programs, new frameworks are proposed for a more reflexive way of dealing with vulnerabilities in technological cultures. Importantly, this book argues for building on the positive meaning of vulnerability in devising strategies for coping with it: by giving space to uncertainty, doubt, and error, or by drifting away from established rules, we may enhance our capacity to cope successfully with vulnerability.

\section{Vulnerability in Technological Cultures: Approach}

In this volume, we develop an approach to key questions in current societies about the risks and benefits of modern science and technology. To do this, our entry point is technological cultures, rather than modern societies; and the key concept is vulnerability, extending the analysis of risk. In this section, we briefly introduce these choices by explaining the focus on technological culture, giving a preliminary definition of vulnerability, and reviewing the differences between vulnerability and risk.

\section{Technological Culture: A New Level of Analysis}

If we take the concept of culture to mean "a group's shared set of meanings, its implicit and explicit messages encoded in social action" (Traweek, 1988), the concept of "technological culture" is used to denote the shared set of assumptions that govern the interactions in modern societies, which are so pervasively constituted by science and technology.

The concept of culture is typically used to highlight whatever humans learn, in contrast to whatever is innate. Thus, it is contrasted with nature: where nature provides humans with base needs and desires, culture provides for content and meaning. Therefore, "culture refers to community-specific ideas about what is true, good, beautiful, and efficient" (Shweder, 2001, p. 3153). These cultural meanings are socially inherited and customary; they constitute a way of life. A cultural account helps to explain why the members of a particular culture say and do things to each other with words, acts, and artifacts. As such, it accounts for the goals, values, and worldviews embraced by a particular group.

The border between the concepts of culture and society is sometimes quite thin. To relate the two, we follow the characterization of culture by Hannerz (1992) in three dimensions. The first dimension is formed by ideas, values, goals, and worldviews. His second dimension is the well-known element that is sometimes called material culture: forms of externalization of ideas, values, and goals in the form of artifacts. Hannerz's third dimension of culture is the social distribution of meanings and artifacts. This third dimension gets us close to the concept of society as constituted by relations between humans, groups, and-from an STS perspective-technologies. Thus, our technological culture largely overlaps in its ontology with modern society as constituted by science and technology (Bijker, 2006). The important difference lies in the implicit research heuristics: studying culture implies following an ethnographic approach that maps not only social structures, but also goals, values, and worldviews. ${ }^{2}$ The term technological culture thus primarily invokes another level of analysis: adding the cultural to the societal (Bijker, 2010).

In this volume, therefore, we use a research heuristic that combines sociological analysis of society's structures and power relations with an ethnographic analysis of the values, goals, and worldviews that govern the interactions, and also provides an STS analysis of the relations between technology and society, between science and politics, and between ecosystems and human communities.

\section{Vulnerability: A Preliminary Definition}

The term vulnerability can be found in many fields, such as economics (e.g., poverty and livelihood studies), climate studies, studies of technological systems (e.g., critical infrastructures), disaster studies, development studies, and anthropology. All these disciplines have their own concepts of vulnerability. ${ }^{3}$ For social scientists, for instance, vulnerability is "the set of socio-economic factors that determine people's ability to cope with stress or change," while climatologists talk about vulnerability in terms of "the likelihood of occurrence and impacts of weather" (Brooks, 2003, p. 2). Alwang and Siegel (2001) review the many kinds of vulnerability in 
academic literature, including technological vulnerability, livelihood vulnerability, structural and proximate vulnerability, nutritional vulnerability, and socioeconomic vulnerability. Some definitions focus on the risks and the stress that people are subject to, or on their powerlessness to respond or cope with these stressors. The focus can also be on the outcome in terms of (welfare) loss (Brooks, 2003), on the limitation of an individual's decisionmaking capacity (biomedicine), or on the risk of being wronged (bioethics) (Levine, 2004, p. 397).

Problems arise when one tries to compare different measurements of vulnerability. Both the object and method of measurement differ across disciplines and thus makes interdisciplinary comparison very difficult. Due to its multiplicity in meaning and measurement, vulnerability as a concept runs the risk of losing its analytical and practical value. To deal with this problem, some clarifying frameworks have been proposed, using classifications of vulnerability by type of technology, scale of disaster, and type of cause (Adger, 2006; Alwang \& Siegel, 2001; N. Brooks, 2003; Gallopín, 2006; Hilhorst \& Bankoff, 2004; Martin, 1996; Murray \& Grubesic, 2007).

Humans can be vulnerable, as can plants, animals, ecosystems, groups, communities, institutions, artifacts, technical systems, and organizations. Vulnerability is an emergent property of systems. Those systems, in our analysis, may be social and physical, cultural and natural, small and big; we will return later to a discussion of the various units of analysis and their implications for the study of vulnerability. We shall also argue below that vulnerability, as an emergent system's property, should not be considered as given, intrinsic, and essential, nor as purely negative. ${ }^{4}$ Rather, we will propose to study it from a constructivist perspective. At this point, it suffices to highlight that a comprehensive characterization of vulnerability requires a description of natural, social, and technical aspects. To characterize the vulnerability of New Orleans asks for a description of hurricane statistics, class and ethnicity distributions in the lower quarters, levees' qualities, and the ecosystem of the marshes (Bijker, 2007). These aspects are embedded seamlessly in the system.

Vulnerability, however, cannot be analyzed by looking only at the inside of a system. It also relates to that system's environment. The same person, clad in many layers of wool, can be invulnerable up in the Himalayas but vulnerable in Hyderabad, India. A characterization of a system's vulnerability thus requires attention to its environment, including the risks that it runs as well as the resources that it may draw upon.

Finally, vulnerability is not purely negative. It is, as we suggested previously, at least inevitable in our highly developed "technological cultures" and "risk societies." In some contexts, it may even assume a slightly positive connotation. Some degree of vulnerability, for example, goes hand in hand with openness to change and willingness to engage with the uncertainties that are associated with learning and innovating.

Our concept of vulnerability thus is hybrid in three important ways. First, it is natural, sociocultural, and technical. Second, it relates to the unit of analysis, as well as to its environment. Third, it can have both negative and positive connotations. This threefold hybridity is important because it raises new questions and thus complements risk-based approaches.

\section{Vulnerability and Risk: A Review}

Vulnerability is a problematic concept-why use it at all? Risk has always played an important role in technological system theories, while vulnerability is a relatively recent addition to the way of thinking about the risks and failures of technological systems. And indeed, the distinction between the two concepts has not always been clear. Several attempts have been made to clarify the relation between risk and vulnerability. In more recent literature, it is generally assumed that vulnerability is a broader concept than risk (Bijker, 2006; Leach, 2008; Sarewitz, Pielke, \& Meykhah, 2003). Risk is often associated with quantitative approaches (risk = probability of hazard $\times$ the impact of hazard); vulnerability, in contrast, is linked to situations that are less specified and more difficult to predict because it results from social processes that are partly outside the system.

This assessment, however, pertains to only one category of risk analysis approaches: the traditional quantitative approach of risk estimation, dominated by engineers and natural scientists. Recent work in risk studies has incorporated more qualitative aspects. These studies can be grouped roughly into four categories: 1) risk perception research, 2) cultural and symbolic studies of risk, 3) risk-society theories, and 4) governance theories related to risk. ${ }^{5}$

Risk perception research emerged since the 1970s, when concerns about new hazards such as the use of pesticides and nuclear power became more prominent in public debates (Slovic, 2000). Risk perception scholars Paul Slovic and Baruch Fischoff conducted large-scale surveys in which they asked how people perceived risks (Lofstedt \& Frewer, 1998), their basic question being "Who fears what, and why?" The risk perception approach builds on the assumption that different people perceive risk in different ways, depending on their experience, position, and agency to change the situation. The risk of traffic is perceived to be less than that of cancer, partly because we can choose not to be part of traffic. Results from studies of 
risk perception have been used to explain and predict why people would oppose specific technologies (Slovic, 1998, 2000). Recently, risk perception scholars have argued for a more democratic control of risk assessment by a closer involvement of laypeople.

What started as a study of individual psychology (often cast in quantitative analyses, subsumed under the heading of "psychometry") developed into a more constructivist view on risk perception in the late 1980s and early 1990s. Risk perception was no longer seen as a purely individual matter, but as something that strongly interrelates with social, cultural, and political factors, such as the role of worldviews, gender, and trust (Lofstedt and Frewer, 1998; Slovic, 2000). Douglas and Wildavsky (1982) argued, for instance, that the factors that determine which risks are perceived as acceptable cannot be explained by individual psychology or objective reality. Instead, risk perceptions develop out of social and cultural processes that are unique to each society and are affected by values, ideologies, and the sociopolitical economic situation (Beck, 1986, 1992; Jasanoff, 1993; Johnson \& Covello, 1987; Krimsky \& Golding, 1992; Nelkin, 1989; Renn, 2005; Wynne, 1989). The key scholar representing these cultural and symbolic studies of risk is the anthropologist Mary Douglas. She was among the first to argue that risk judgments have a clear political, moral, and aesthetic dimension and that risks are socially constructed (Douglas, 1992; Lupton, 1999).

The third category, risk society theories, is represented by scholars such as Ulrich Beck and Anthony Giddens. They are primarily interested in how conceptions of risk are related to modernity. According to Beck (1992), we are experiencing a transition from an industrial society to a "risk society." In a risk society, risks are uncertain and difficult to calculate and predict and therefore can have a devastating impact on society. Rather than the "logic of wealth distribution," which structured earlier societies, the "logic of risk distribution" is the key mechanism in a risk society. The normative aim of the risk society is achieving safety (rather than equality, as in the industrial society) and this goal is framed in negative and defensive terms: "one is no longer concerned with attaining something 'good' but rather with preventing the worst" (Beck, 1992, p. 49). In a similar vein, Giddens stresses that risks are always present in the abundant choices we have, in the technologies we use, and in the experts we trust. Just as Beck does, Giddens emphasizes that we live in a "risk culture," where risks are created by humans and have a more far-reaching effect because of the globalized nature of these risks (Giddens, 1990, 1991). However, unlike Beck, Giddone ctrocese $n$ nt nnlv the risks and dangers, but also the opportunities of modern societies, which resonates with our plea to see vulnerability not as being only or always negative. In this discussion about societal risks, Zymunt Bauman also plays a significant role. In Liquid Modernity (2000) (c.f. Beck's "risk society") Bauman discusses the emergence of risks and uncertainties and relates them to the unstructured (liquid) form of today's societies.

Theories of risk governance, the fourth category of risk approaches, primarily deal with the question of how risks are regulated and communicated in contemporary society. Scholars in this category stress that risk governance must deal with both the physical and the social dimensions of risk. This requires, some argue, an integration of the realistic and constructivist views of risk (Renn, 2005). In the decision-analytical approach, for example, risk is not "regarded as an objective property of an object or situation but as a subjective mental construction based on personal beliefs about the occurrence of specific outcomes of an event or action" (Otway \& Peltu, 1985, p. 118). Already in the early 1990s, scholars such as Sheila Jasanoff proposed an integration of the quantitative and non-quantitative approach of risk analysis. According to Jasanoff, both approaches exist on a single continuum but capture different aspects of the complex and multidimensional reality of risks. She argues that "both are needed to produce anything like a comprehensive accounting of the nature and extent of risk in a technological society" (Jasanoff, 1993, p. 124). Klinke and Renn try to overcome the dual nature of risk (realism versus constructivism) and propose a deliberative style of regulation and management of risk to improve "the effectiveness, efficiency, and political feasibility of risk management procedures" (Klinke and Renn, 2002, p. 1091).

Stressing the role of uncertainty in dealing with risk at the policy level, van Asselt and Vos (2006) have coined the term uncertainty paradox, which refers to situations in which the uncertainty of risks is recognized and scientific knowledge is proposed to resolve this uncertainty. Studying cases of risk regulation at the level of the European Union or governmental institutions, these studies critically investigate the weak spots in risk governance. Risk communication to the wider public is also a topic of investigation in this category. Works by Ragnar Löfstedt, David Slavin and Frédéric Bouder, for instance, have linked the issue of communication about food safety in the European Union and the regulation of pharmaceuticals to wider issues of public trust and communicating uncertainty (Bouder, Slavin, \& Löfstedt, 2007).

The constructivist risk approach, in which risk does not exist as an unchangeable objective fact but is seen as the outcome of social processes, 
can be found, in varying degrees, in all four categories. Moreover, such an approach to risk resembles the constructivist approach to vulnerability (Hilgartner, 1992; Renn, 2005; Summerton \& Berner, 2003). Not surprisingly, some authors have tried to integrate both concepts. Brooks (2003) argues that this will facilitate the communication between different disciplines and improve the management of threats such as caused by climate change. He proposes a differentiation between biophysical and social vulnerability. Biophysical vulnerability is concerned with the impact of a hazard. It is about the frequency and severity of damage, and as such, has much in common with the concept of risk. Social vulnerability, on the other hand, is the internal state of a system. This is determined by, for example, poverty, inequality, and (lack of) housing.

In most risk studies, risk has been defined as a negative phenomenon. According to Lupton (1999), "risk is now widely used to explain deviations from the norm, misfortune, and frightening events" (p. 3). Douglas also argues that "risk refers only to negative outcomes. The word has been pre-empted to mean bad risks. ... The language of risk is reserved as a specialized lexical register for political talk about the undesirable outcomes" (Douglas, 1992, p. 24). Although Lupton acknowledges positive approaches to risk taking (for example, people who like "extreme" activities such as bungee jumping, skydiving, or ice climbing), generally, risk is seen as something to be avoided.

Our preliminary conceptual analysis so far has made clear that the concepts of risk and vulnerability are typically employed in different vocabularies. We want to use these vocabularies, which we have tentatively listed in table 1.1, for exploring the differences between the concepts of risk and vulnerability. We do not want to reify these vocabularies into two separate languages because that would underline the differences rather than the complementarities between risk and vulnerability. Instead, to push the language metaphor a bit further, we want to experiment with new "dialects" that combine these two languages and the richness of both concepts. Playing with such dialects will help us to combine the concepts of risk and vulnerability in new and insightful ways. ${ }^{6}$

The vocabulary of risk is the more institutional and official of the two, which is perhaps not surprisingly given its long standing in official policymaking. This vocabulary is also quite clear, as it relies on relatively precisely defined and broadly recognized terms. The vocabulary of vulnerability, on the other hand, is more plain and contextual. It is also fuzzier and uses less well defined terms. A clear example of this is the tandem
Table 1.1

Different vocabularies associated with risk and vulnerability

\begin{tabular}{ll}
\hline Risk & Vulnerability \\
\hline Society & Culture \\
Institution & Community \\
Security & Solidarity \\
Control & Opening up \\
Stability & Non-alignment \\
Closure & Dissent \\
Legality & Justice \\
Probability & Ethics \\
Uncertainty & Unpredictability \\
Indeterminacy & Surprise \\
Regulatory & Consequential \\
Prevention & Precaution \\
Procedure & Prudence \\
Sophistication & Humility \\
\hline
\end{tabular}

prevention-precaution, where the first has spurred decades of science, technology, and practices, while the latter still invokes deep political and theoretical debate. Risk vocabulary is prosaic in offering clear descriptions and definitions, often with quantitative means, whereas vulnerability vocabulary is more poetic and qualitative, adding emotions and openness to alternative imaginations.

In this new dialect that we seek to develop by adding vulnerability vocabulary to risk vocabulary, the cultural is added to the societal. Gemeinschaft is added to Gesellschaft, and solidarity to security. To an important emphasis on legal structures and relations, an open-ended and less focused attention to justice is added. To complement a probabilistic analysis of problems and decision making, a qualitative and discourse-based attention to ethical questions is called for. Proper procedures are important and should be explicated as much as possible to build sound democratic frameworks for dealing with hazards, but a broader notion of prudence needs to be added in recognition of the inherent unpredictability of science and technology and openness of cultural developments. Humility in recognizing the limitations of the human capacity to harness the world should complement sophistication in finding social-scientific and technological means to control risks (Jasanoff, 2007). 


\section{Studying Vulnerability: Units of Analysis}

After comparing the concepts of risk and vulnerability, we will now continue our review of the literature by concentrating on vulnerability. We will structure this review by discussing three units of analysis: the human world, the human-made world, and the natural world. Humans, both as individuals and as social ensembles, constitute the first unit of analysis; socio-technical systems and organizations are the second; and ecosystems are added to compensate for the anthropocentric biases of the first two. After thus reviewing the literature on the vulnerability of humans and organizations, as well as of ecosystems, we will turn to a discussion of research strategies and heuristics.

\section{Vulnerability of People}

Human beings can be harmed, they can die, and their communities may be disrupted or demolished. However, not all individuals are equally vulnerable. Much of the scholarly attention to the vulnerability of people has focused on developing countries (Bankoff, 2001; Bhatt, 1998; Hilhorst and Bankoff, 2004). Often, researchers in this area use the notion of vulnerability to move away from a risk-based approach, which they consider too limited in scope and explanatory power. Hilhorst and Bankoff (2004), for instance, claim that a vulnerability approach allows for more adequate measurement of exposure to risk because it incorporates social factors. Disasters, they argue, are affected by social power structures that generate unequal exposure to risk. In particular, they suggest that quantitative riskbased approaches are too limited because they do not incorporate factors such as class, gender, and ethnicity. Their vulnerability approach, on the other hand, "seeks to combine the risk that people and communities are exposed to with their social, economic, and cultural abilities to cope with ties may chancurred" (Ibid., p. 2). John Twigg adds that such vulnerabilities may change over time: "More and more people have become vulnerable to hazards because of changes in their social, economic, cultural, and political environment and circumstances." (Twigg, 1998, p. 2)

An analysis of the social dynamics of international and economic relations may contribute to our understanding of how development projects generate vulnerability, according to Hilhorst and Bankoff (2004). Thus, Martin (1996) proposes to investigate whether corporate or political interests contribute to maintaining the causes of vulnerability or the vulnerability itself. Bankoff (2001, p. 19) criticizes vulnerability approaches in which tropical areas or "developing countries" are designated as "disease-ridden, poverty-stricken, and disaster-prone." Specifically, Bankoff analyzed the history of Western discourse on developing countries since the 17th century and he distinguishes three such discourses: the discourse of tropicality, of development, and of (vulnerability to) disasters. He argues that these discourses are characterized by a Western bias and that it is incorrect to associate poverty with vulnerability automatically. Moreover, in his view, it is not justified to label specific parts of the world as inherently more dangerous than others. A result of this Western way of labeling, he claims, is that some "vulnerable parts of the world" suffer from too much Western interference. Hilhorst (2004) asks us to recognize that labeling people as vulnerable is a political act, and that this may open the door to top-down interventions. A conceptualization of vulnerability, thus, also should include relevant power structures and, more important, the agency of people. By positioning the agency of people at the center of research and policy agendas, Hilhorst and Bankoff (2004) aim to move beyond a technocratic conceptualization of vulnerability and beyond a vulnerability that is simplistically defined in terms of power differences.

Rather than developing general models for understanding vulnerability, Mihir Bhatt (1998) proposes to focus on the life stories of victims. Such life stories are taken seriously as accounts of vulnerability experience in the chapters in this book by Julia Quartz, Esha Shah, and Shiv Visvanathan and Teesta Setelvad. By providing space for human suffering and social disruption, vulnerability directs our focus to the human rather than the economic rationale (Sarewitz et al., 2003), linking vulnerability to a discourse of justice and human rights. Vulnerability is a story that is created twice: the first time when the hazard occurs, and the second time when it leaves its cultural and social imprint upon people's recollections. Memory thus plays a key role in dealing with vulnerability; see this book's chapters by Visvanathan and Setelvad, Shah, and Jasanoff; see also Radstone (2008) and Radstone and Hodgkin (2003). Life stories and narratives about disastrous events might even help victims and others recover from a disaster. In this vein, Vale and Campanella (2005) explore the notion of "narratives of resilience." Such narratives "are constructed collective voices that expose a longing to render tragedy in uplifting terms or to append a spiritual or faith-based element to the suffering at hand" (p. 15). In this way, human vulnerability and suffering can be redefined in positive terms, emphasizing how critical events can eventually bring about progress and innovation.

The literature on the vulnerability of people in developing countries thus sees social structures as the prime cause of people's vulnerability in the global south. From this perspective, vulnerability is not an inherent 
property of an individual or a group; rather, it is socially constructed and political by nature. (We will return to this when discussing our research heuristics in the next section.) This literature allows us to broaden the concept of vulnerability by paying attention to issues of development, poverty, justice, and life stories. Most existing research on these questions, however, generally ignores the role of technology in the construction of vulnerability. In this volume, we seek to remedy that neglect.

\section{Vulnerability in Technological Systems and Organizations}

The second unit of analysis that we want to distinguish is non-human. Here, we do not want to limit ourselves to artifacts but analyze socio-technical systems and organizations as well. In plain parlance, this includes objects such as aircraft, large technical systems such as nuclear power plants, and organizations such as a military defense system.

Much scientific discourse on vulnerability is rooted in a conceptualization of society as increasingly complex and constituted by science and technology. In the risk society posited by Beck $(1986,1992)$, the implications of modern science and technology are more important determinants of societal development than the production relations that described the development of industrial societies. In the "network society" proposed by Manuel Castells (1996), infrastructures have become more and more intertwined. This intertwinement has important implications for the vulnerability of this society. According to Bekkers and Thaens (2005), "our dependence on ICT [Information and Communication Technology] and the fact that they are all interconnected makes our societies vulnerable. ... disturbance in one of these networks could spread relatively easily to the networks" (p. 37). Lukasik (2003) argues that dependencies between systems are often unplanned and unknown. Winner (2004) agrees that dependency on technological systems is a source of vulnerability, but that, paradoxically, people in the global north are quite happy with it because they consider it a prerequisite for progress and freedom. The complexity of systems increases as a result of these interdependencies, and no single person or organization is fully knowledgeable about the whole system. As a result of the increasing complexity and intertwinement of these systems, Lukasik argues, the impacts of system failures are aggravated. Moreover, if the system fails, no single organization can fix the problems.

The relation between complexity and vulnerability is a key focus in the Normal Accidents Theory (NAT) of Perrow (1984/1999). He demonstrated that organizations do not behave as rationally as is usually assumed: decisions may not be clear and straightforward, priorities do not always match, and it can be hard to achieve a working system of social control in organizations. Key dimensions in his theory about technical systems are their complexity and the coupling of their components. The more tightly coupled and the more complex a system is, the more it is prone to failure. ${ }^{7}$

Researchers in the High Reliability Organization (HRO) approach emphasize the opposite. In this approach, it is argued that systems that should be highly vulnerable according to Perrow's criteria actually do not fail very often. This research thus investigates critical infrastructures, such as nuclear power systems and air traffic control, and seeks to explain why these systems are so remarkably reliable (Hopkins, 2001; La Porte, 1991; Sagan, 1993). Scott Sagan compares NAT and HRO in an analysis of the command and control of nuclear weapons in the United States and the prevention of nuclear war. He argues that one of the factors that explains the positive safety records in high-risk sectors is the development of a "high reliability culture in decentralized and continually practiced operations" (Sagan, 1993, p. 17). NAT and HRO theorists also differ in their assessment of the effectiveness of safety measures such as the creation of redundancy in systems. Whereas HRO theorists believe in creating redundancies to make organizations safer, NAT focuses on the potentially negative effects of redundancy: redundant systems are less safe than their designers often believe because redundancy makes system failures and the role of human error less visible, and system operators may think that they can take more risks.

However, NAT has been criticized for being too static a theory. Karl Weick (1990), for example, shows that tight coupling can change over time. In his detailed analysis of the Tenerife airport disaster in 1977, he shows that over time, systems can develop from linear to complex, by which they grow more vulnerable. He thus argues that complexity and tight coupling are not fixed and time-independent properties of a system. In a more recent article, Schulman et al. (2004) analyze a case study of an electricity control room in California and conclude that even if the organization can be characterized by tight coupling and complex interactions, this does not necessarily imply a vulnerable system: "at least in the case of the electricity critical infrastructure, complexity and tight-coupling actually can be important resources for high reliability management" (p. 15). Complexity gives opportunities for variations in actions and thus "allows for multiple strategies of resilience" (p. 26). Moreover, "loosely coupled, decentralized systems ... present many more independent targets to terrorists-they can strike anywhere and, while they may not bring down major portions of the grid, they can still score their points in the psychological game of terror and vulnerability" (p. 26). 
This tension between the need for organizational flexibility to allow for "strategies of resilience" and the risks of too much flexibility is extensively discussed in scholarly literature on vulnerability. Closely related to this discussion is the role of rules, protocols, and procedures in the management of vulnerability. As Schulman et al. argue: "Part of the [control room] experience is to know when not to follow procedures ... there are bad days when a procedure doesn't cover it, and then you have to use your wits" (Schulman et al., 2004, p. 23). It is generally acknowledged in the literature that (all) organizations tend to deviate from strict rules and protocols, but the literature differs in its assessment of the dangers or benefits of this practice.

This issue has also been addressed in the man-made disaster (MMD) model, developed by Barry Turner in the 1970s and later elaborated upon by Nick Pidgeon (1997). This model especially focuses on the phase before accidents happen: the "disaster incubation period." Even though everyone involved is really committed to the safe operation of the system, there are invisible, normal organizational processes that might harm safety. Signals that something is wrong are ignored or misunderstood, and when a disaster happens, it is too late to do anything about it. It typically takes a long time before the hidden danger turns into a disaster. Events mix in complex, unexpected, and unintended ways and can ultimately result in disaster. The MMD model pays much attention to cultural factors in the perception and interpretations of risks and hazards: "Culture is positioned at the heart of the system vulnerability problem, because of its role in shaping blindness to certain forms of hazard" (Pidgeon, 1997, p. 5). This cultural blindness should be solved by institutional design to make the implications of the blindness less dangerous. In contrast to NAT, which sees the cause for accidents mainly in the characteristics of technical systems, MMD sees humans as the prime cause and potential solvers of problems (Rijpma, 2003).

A similar focus on the phase preceding an accident is found in work by Scott Snook (2000). He introduces the concept of "practical drift" to describe how a gradual deviation from organizational rules can eventually lead to disaster. He analyzed the 1994 incident of two US Air Force fighter planes shooting down two US Army helicopters with UN peacekeepers over northern Iraq. The fighters erroneously identified the US Black Hawk helicopters as enemy Iraqi Hinds. An Airborne Warning and Control System (AWACS) aircraft, with highly advanced radar and communication equipment, was in place to monitor air traffic and communicate with aircraft in the area, but it did not act to keep the fighter planes from engaging and shooting the friendly helicopters. All 26 people aboard the helicopters died. No serious technical malfunction could be found, and no single human error could explain how this tragedy could occur. Consequently, the causes of the accident had to be sought in the social and organizational fabric of military operations. By investigating the incident and tracking the events that led up to the fatal shooting, Snook was able to formulate a theory of organizational breakdown that offers an explanation of how a tragedy like the friendly-fire incident over northern Iraq can happeneven in an organization that is specifically designed to avoid this kind of accident. By developing accounts of the accident on several levels, from the individual, group, and organizational levels to a cross-level account, Snook builds his "theory of practical drift."

The disasters with the space shuttles Challenger (1986) and Columbia (2003) have also been explained by the occurrence of "safety drift" in the phase preceding the accidents (Farjoun, 2005; Vaughan, 1996). In the organization of the National Aeronautics and Space Administration (NASA), a gradual shift from safety to efficiency took place. Diane Vaughan, in her study of the explosion of the Challenger space shuttle, argues that a "normalization of deviance" at NASA ultimately resulted in the mistakes that caused the Challenger disaster. After an accident, Farjoun argues, an organization is temporarily more elastic and flexible and more willing to comply with stricter safety rules-a mechanism that has also been described by Snook. However, this strategy of implementing stricter rules can be risky too. Wackers and Kørte, in their analysis of a helicopter accident over the North Sea in 1997, point at the role of "gaps" between protocols and practices-a gap that is likely to be reinforced by stricter, more standardized rules: "A focus on the messiness of drift and vulnerability is at variance with current quality assurance paradigms as they appear in ISO9000 codes and standards. These require a rigidity, stringency, and consistency that do not conform to this fluid reality" (Wackers \& Kørte, 2003, p. 204). This conclusion resonates with the chapter in this book by Hommels et al., which argues that increased standardization (in regulatory regimes) probably increases the gap with local practices, potentially resulting in new vulnerabilities.

\section{Vulnerability of Ecosystems}

Our discussions of the study of vulnerability until now have had an unmistakable anthropocentric bias. Therefore, it is worth highlighting ecosystems as a third unit of analysis. In this book, however, we will not study the vulnerability of ecosystems separately, nor use a biological and ecological 
research perspective. Rather, this subsection serves to underscore the key role of ecosystems in analyzing the vulnerability of human communities. Hazards that affect an ecosystem often will have detrimental effects on human communities and thus add to the vulnerability of those communities. If strategies of coping with the vulnerability of people or technological systems do not take into account the possible effects on the relevant ecosystems, this may backfire and result in new vulnerabilities for those people and socio-technical systems.

Since the 1980s, the relation between ecological hazards and the vulnerability of people has been on the political and research agenda (Cutter, 2006). The "environmental justice movement" in the United States started with the recognition that environmental hazards impinge differently on different social groups and places. By 1992, the US Environmental Protection Agency (EPA) established an Office of Environmental Equity. Environmental justice in this framing seeks to guarantee protection from environmental degradation, prevention of adverse health effects of deteriorating ecosystems, the shifting of the burden of proof from victims to polluters, and the redressing of impacts with remedial actions. Environmental justice, then, also appears to be quite anthropocentric by affording a central place to the negative impact that ecological hazards have on people and society. Environmental justice indeed is a standard conception of justice (which can be operationalized by referring to such factors as class, ethnicity, religion, and gender), with a specific focus on its violation by environmental hazards.

At the other end of the spectrum between humans and nature stands "ecological justice" (Baxter, 2004), which makes a plea for doing justice to animals, plants, nature, and ecological systems. In this philosophy, we need an adequate, practical, and moral response to the pressure that Homo sapiens has recently been exerting upon the other species of this planet. However justified this idea may be, it does not form part of the agenda of this volume for two reasons. First, our scientific scope has limitations; it does not include the biosciences. Second, we want to argue for transcending the distinction between nature and humans.

By taking seriously our plea to add the natural as a fourth element to the technical, the social, and the cultural, we aim to transcend the distinction between the human-built world and the ecology. In our conceptual framework, ecosystems are an important part of our technological cultures. For example, this would result in a broader conception of justice than captured by "environmental justice" or "ecological justice." Such ecological justice (if we stick to that term and try to broaden it) calls for the right for all people to live in their own ecological circumstances. Embracing such a principle of ecological justice would, for example, fundamentally change the discourse on the vulnerability of the adivasi people in India, who are displaced to make way for big infrastructural works such as dams. Classic forms of justice would call for compensation measures: new land or some money. Our broad principle of ecological justice would question the right to move these people from their ecological environment in the first place, recognizing that their technological culture is inextricably bound to that specific ecology. When broadened in this way, it is similar to Shiv Visvanathan's concept of cognitive justice: the right of every people to have their own style and system of knowledge.

Our broad principle of ecological justice also resembles Oliver-Smith's concept of vulnerability as a "political ecological concept." "Vulnerability is the conceptual nexus that links the relationship that people have with their environment to social forces and institutions and the cultural values that sustain or contest them" (2007, p. 10). By locating vulnerability at the intersection between nature and culture, Oliver-Smith enables us to focus on the totality of relationships in a given situation to prevent environmental determinism. So, even though the ecological system as the third unit of analysis does not figure explicitly in this volume, recognizing it as part of the people-technology-nature triad is an important building block in conceptualizing risk and vulnerability, and as such, it is reflected in the thinking and researching of the authors of this volume. ${ }^{8}$

\section{Heuristics of Studying Vulnerabilities}

We have now sketched our general approach to vulnerability, reviewed the relationship with the concept of risk, and discussed three important units of analysis. In addition, we have identified three different forms of heterogeneity. The first heterogeneity of vulnerability is that vulnerability pertains to the natural, the social, and the technical; the second is that vulnerability is a system's property, and at the same time, it is context dependent; and the third is that vulnerability is inevitable, but it is not automatically negative-it can be positive. These forms of heterogeneity can be translated into research heuristics for studying vulnerability. In this final section of this introduction, we shall elaborate the research heuristics that inform the chapters in this book. The first heuristic is an ethnographic approach to studying vulnerability by choosing as a research entry point technological culture rather than modern society. The second is to employ a constructivist approach; and the third is to transcend an exclusively 
negative connotation of vulnerability and also look for more charitable aspects.

\section{An Ethnography of Vulnerability in Technological Cultures}

We already argued in the beginning of this introduction that technologies are used to increase reliability and enhance safety, but they also cause vulnerability. Medical equipment in intensive care units allows a better monitoring of newborn babies, and higher dikes help to prevent flooding. But being dependent on electrical networks makes us vulnerable to power outages, and if you do not have dikes, they cannot break. Thus, vulnerability is a characteristic of technological cultures.

Therefore, we propose to study vulnerabilities that happen in technological cultures. The first implication is to trace vulnerabilities' relation to technologies. This can be a lack of technologies (as when the lack of simple water purification technologies causes a high mortality by cholera), or it can be the unintended effects of the use of technologies (such as the increased financial debts of Indian farmers because of their need to buy chemical pesticides). Almost all instances of vulnerability in today's societies are shaped by technologies. At the same time, our default defense mechanism against vulnerability is to call upon technology too. To improve patient safety in a high-risk and technology-intensive environment such as an intensive care unit, we typically invest in more technologies: electronic technologies for monitoring and social technologies of protocol to discipline doctors and nurses. When the livelihoods of hand-weaving communities in India are threatened by globalizing markets because their customers start buying mass-produced synthetic and brightly printed fabrics, one reaction is to invest in the technology of the power loom and embrace the administrative technologies of centralized marketing. When the Netherlands is threatened by rising sea levels due to climate change, the country responds by investing in more technology (such as levees).

The second implication of studying vulnerabilities happening in technological cultures is to study vulnerability in vivo. This requires the use of ethnographic research methods and the investigation of these technologies with a special sensitivity to the social and cultural dimensions of technology by drawing on the work in STS of researchers such as Hackett et al. (2008). Studying vulnerabilities in technological culture will help to bring out the interactions between the various dimensions of vulnerability: technological, scientific, social, economic, political, ethical, and cultural. We will elaborate on this in the next section.

\section{A Constructivist Perspective on Vulnerability}

Taking a constructivist perspective means that we analyze vulnerabilities in their historical, political, economic, and geographical context. We propose to view vulnerability not as an intrinsic and static characteristic, but rather as an emergent property that will depend on and result from specific circumstances. A failure of an elevator in a hospital may have more severe consequences than a similar failure in an apartment building. Thus, we assume that vulnerabilities are not fixed properties of systems; rather, they are context dependent and usually change over time. The chapters in the first part of this book provide detailed examples of this emergent character of vulnerability.

In some cases, people's vulnerability might not be resolved, but the form of vulnerability may change over time. In the case of emergency communication, for instance, a major problem can be lack of coordination. In the Netherlands, for example, various different emergency units (police, fire brigade, ambulance, etc.) had trouble communicating with each other because they had different radio frequencies. After the introduction of ICT and a new technical standard, new vulnerabilities emerged in the form of an increased dependence on a small number of network suppliers (Hommels \& Cleophas, 2008). Jessica Mesman gives another example in her chapter on critical care medicine in this book. She shows how the practice of doublechecking medication by nurses (intended to reduce patient vulnerability) may lead to a disturbance of the concentration of the nurses who are asked to do this double-check. This may cause a nurse to commit errors, resulting in new forms of vulnerability for the patient. Also, the way of coping with vulnerabilities differs in different contexts (e.g., the way of dealing with water management in the United States and in the Netherlands), depending on the differences in technological culture (Bijker, 2007). Several authors in this volume scrutinize these "local" specificities of vulnerability.

Furthermore, a focus on vulnerability means taking seriously the role of vulnerable groups or people in technological cultures. People may be vulnerable, and their situation may seem inescapable, but applying a constructivist perspective may offer new perspectives and coping strategies. Where, how, and when does vulnerability become a problem, and to whom? Which vulnerabilities do different social groups identify? In many highrisk environments, safety and vulnerability are aspects that are negotiated among the actors involved. In railway maintenance, for example, tradeoffs have to be made between productivity (getting the job done on time) and the safety of the maintenance workers. How are safety and reliability 
negotiated? What is the role of risk perceptions or estimations of a system's vulnerability for actions that were not taken? A constructivist perspective on vulnerability means that we take a close look at the negotiations among actors about the safety or risks involved in the systems and organizations in which they work.

A constructivist approach also opens up alternative strategies. "Things could have been otherwise," as one of the key dictums of constructivism goes. So, instead of the default response of expecting technology to defend against vulnerability, other choices could be made, and in some cases, they have been made. Safety in intensive care units could be enhanced by other forms of social interaction and training; hand-loom weavers could try to innovate their designs and logistics so as to cater to high-end international niche markets; rather than raising its river dikes, the Netherlands has embraced a new program called "more space to the rivers," which aims to increase the water storage capacity of the rivers by allowing selected farm lands next to the river to flood.

\section{Vulnerability as Potentially Positive}

When we say that a system is vulnerable, we typically want to say that it is susceptible to harm. Vulnerability thus is often characterized as a property or characteristic of systems, though a socially constructed one. Mostly, vulnerability is used as a specific rather than a generic characteristic: a city may be vulnerable to damage by specific disturbances such as floods and not be vulnerable to damage by other disturbances such as earthquakes. In such contexts, vulnerability is generally taken as something negative to be avoided, and harnessed if it cannot be avoided.

The third heuristic that we used in this volume is that vulnerability need not be considered exclusively negative. Vulnerability of a culture can even be considered a necessary condition for its survival: only when a culture is capable of learning, innovating, and reacting to external threats in a flexible manner will it be sustainable in the long run. To be innovative, Schumpeter (1942) has argued, one has to be creative and take risks, and that implies some degree of vulnerability. This idea is taken further by the notion of "creative dissent," discussed in the chapter by Shambu Prasad in this volume, which argues that dissent is necessary to innovate and that innovation, in turn, is necessary for coping with the vulnerabilities that India faces today.

Snook's theory on practical drift describes how gradual deviation from protocols can lead to accidents, and it highlights the role that rules can play in making an organization safer. His example of the friendly-fire accident in northern Iraq shows how a gradual deviation from the rules results in an increasingly vulnerable organization. This might lead some to the conclusion to apply rules more strictly. Others have argued that flexible application of the rules can be beneficial or even necessary for normal functioning of technological systems and organizations. It has also been argued that for a smooth functioning of technical systems, it is sometimes necessary to take risks. When air traffic controllers want to upset the air traffic system (for example, because of a labor conflict), they do not need to strikeworking to the rule is enough to obstruct the system. John Law's analysis of the Ladbroke Grove train accident in $1999^{9}$ provides a good example of the positive effects of flexible rule following for the "normal" functioning of technological systems. The signalers who had to stop a train if it passed a red light had developed a practice of waiting because they knew from experience that this signal would normally be turned to green within 20 seconds. This practice (although against the rules) usually guaranteed a quick and accident-free train passage-but not in this case: "waiting and seeing" on that fatal day caused a major accident.) In other words, a system that always follows strict rules will probably not function well for any prolonged period. A culture that is not also a bit vulnerable will not survive.

Another concept that highlights a positive aspect of vulnerability by stressing the need for flexibility and improvisation is bricolage. The notion of bricolage (Ciborra, 2000) starts from the idea that improvisation and tinkering are necessary strategies when dealing with occupational risks under time constraints. In chapter 10 of this volume, "Vulnerable Practices: Organizing through Bricolage in Railroad Maintenance," Johan Sanne argues that if railway maintenance technicians would be less productive and less efficient-and perhaps even less safe-if they did not act as "bricoleurs." After all, rules do not apply to all situations under all circumstances, so some creativity is necessary. At the same time, Sanne acknowledges that bricolage can be risky because procedures and resources will not be improved so long as the maintenance technicians manage to do their jobs successfully (by using bricolage), thus "hiding" potential weak spots in their practices. This can lead to increasing negative vulnerability.

This argument about positive vulnerability mirrors the warnings that historians and sociologists of technology have regularly made against a belief in "technological fixes." As sociologist Benjamin Sims observed when introducing a special panel on Hurricane Katrina at the 2005 Society for Social Studies of Science (4S) meeting: "One danger of relying too much on technological fixes is that these typically create yet more layers of infrastructure, which can make emergency response organizations 
even less likely to plan for contingencies in which critical infrastructure is destroyed" (Sims, 2007, p. 115). It is, we think, also in line with the recent attention that has been paid to the functioning of what Thomas Hughes refers to as "messy complex systems" (Hughes, 1998). Messiness, initially, does not exactly sound as solid, trustworthy, terrorist-proof, and invulnerable. But though such messiness may induce vulnerabilities, it may also make a system more flexible so as to better react to unforeseen circumstances. Also reflecting on Hurricane Katrina, Jameson Wetmore (2007) thus argued:

The loose system of distributed responsibilities that is often associated with large socio-technical systems can work well. It allows different groups with different visions to participate without forcing them to strictly adhere to predefined roles fo which they may not be suitable. The differences can lead to conflicts, which must then be negotiated, but such flexibility often allows differing opinions of what the systems should look like to coexist. Thus, different groups may end up attacking the same problem from different directions, making the system more robust and ultimately increasing in effectiveness. (pp. 123-124)

These observations apply more generally, we think, when analyzing the vulnerability of technological culture. When the Netherlands moved away from its centuries-old, decentralized, and democratic form of water management to a more centralized system of storm surge barriers and other advanced and large technological systems, it created a system of coastal defense that may be less vulnerable, but it is also less flexible.

In sum, the third heuristic for studying vulnerability calls for attention to the non-negative aspects of vulnerability. Vulnerability also implies some capacity to recover and to renew, and it often implies an openness and flexibility that may allow for new and creative ways to act and muster new capabilities. We can think of scenarios in which more flexibility (with the associated vulnerability) would have been appreciated.

\section{Conclusion}

The three key questions that will be discussed in the three parts of this volume are: (1) What are we studying by focusing on vulnerability? (2) How should we study it? (3) Why should we bother?

The first part explores vulnerability in technological cultures by discussing empirical studies of key domains. These domains range from large-scale chemical disasters to agriculture and medical practices, and geographically from India to the Netherlands to the United States. By taking such a broad approach, we seek a better understanding of what vulnerability is and does.
Using a fine-grained description will show where, how, and when vulnerability becomes a problem or is an asset. The empirical domains and case studies, considered together, span the scope of issues to be addressed in this book: a broad range of technological sectors and societal issues, publicly and privately funded and managed technologies, issues related to the global north and south, and historical and contemporaneous developments.

The second part of this book proposes conceptual frameworks for the empirical description and theoretical analysis of the ambiguous and potentially positive character of vulnerability. ${ }^{10}$ In most instances, the vulnerability will have both sides: the negative meaning that is commonly associated with vulnerability, and the more positive meaning that is associated with flexibility, innovation, and development. We have argued that vulnerability is not necessarily something negative; it might even be a necessary condition for innovation in technological cultures. Our book focuses on concepts that illustrate the ambiguity, context-dependency, and constructed character of the vulnerability problem. By applying these concepts to empirical examples, we show their usefulness in the study of vulnerability.

Finally, in the third part, we will investigate which implications the various analyses of vulnerability may have for addressing issues of politics and governance of risk and vulnerability. What are the practical implications for addressing political questions of governing vulnerable technological cultures?

\section{Notes}

1. For revising this introduction, the close reading and insightful suggestions by Jane Summerton have been very valuable. In the next stages of rewriting, intensive discussions with Shiv Visvanathan, Annapurna Mamidipudi, Ranjit Pal Singh, Frederic Bouder, Koen Beumer, and Johanna Höffken have been important. Finally the comments by two anonymous reviewers were very pertinent and helpful.

2. With the phrase ethnographic approach, we do not denote only a full-blown anthropological field study; we also seek to highlight this analysis of a life world from the inside.

3. For an example of the multiplicity of applications and definitions, see Cutter $(1993,2006)$.

4. Considering vulnerability as an intrinsic property of technological systems would be an essentialist position and can be associated with technological determinism. Therefore, we stress that vulnerability is an "emergent" property, a quality that gets built into systems over time, by actors, in specific contexts. Yet we acknowledge 
Sally Wyatt's provocative statement that "our guilty secret in STS is that really we are all technological determinists" (Wyatt, 2008, p. 175), as we do take seriously the obduracy that emergent properties of technology can acquire over time.

5. This categorization is (loosely) based on the one by Deborah Lupton (1999).

6. We are aware that others, like Ben Wisner and Piers Blaikie (e.g. Wisner, Blaikie, Cannon, \& Davis, 1994), have identified points of dialogue with risk theories and risk society theory in particular.

7. Perrow (2007) refined the distinction between dependence and interdependence of social organizations in this context. Whereas dependence is something that should be avoided, interdependence should be promoted: "Power involves dependencies; safety and security in the infrastructure involves interdependencies" (p. 296). Interdependence is a situation in which there are many actors involved, producers, suppliers, and multiple customers: "if anyone of these fails, there are alternative sources of producers, suppliers, and customers" (p. 300).

8. If nature were to be explicitly studied, we would of course have conceptualized it as socially constructed: as informed by recent STS work in general and work in the sociology of scientific knowledge (SSK) specifically.

9. John Law, "Ladbroke Grove, or How to Think about Failing Systems," published by the Centre for Science Studies, Lancaster University, at http://www.lancs.ac.uk/ fass/sociology/research/publications/papers/law-ladbroke-grove-failing-systems.pdf.

10. The distinction between parts 1 and 2 is one of emphasis: all chapters in the first part employ sophisticated conceptual frameworks, and all chapters in the second part are empirically grounded. 
To discuss vulnerability in technological cultures requires that we first identify what to study. Therefore, the first part of this volume is devoted to gaining a better understanding of what vulnerability is and does. Based on historical as well as contemporary accounts, these empirical chapters provide a detailed exploration of the problem of vulnerability in technological cultures and demonstrate how vulnerability is an emergent and relational property that pervades everyday life. Each of the five chapters shows when, where, and how vulnerability affects people's lives and the socio-technical structures they live in.

The set of case studies in part I spans different technological domains, such as agriculture, medicine, and the chemical industry. In addition, the chapters display a great variety of research materials and styles. Empirical material includes in-depth interviews with policy makers, ethnographic observations in hospitals, and the highly charged testimonies of victims. Moreover, the style of telling these stories differs with each author, ranging from an evocative and politically engaging style in chapter 6, "Narratives of Vulnerability and Violence: Retelling the Gujarat Riots," by Shiv Visvanathan and Teesta Setelvad, to a more detached academic tone in other chapters. The styles of presentation and analysis also differ strategically between the authors in order to give full credit to the varied character of the empirical material and the issues at stake. If we want to engage seriously with the vulnerability of people in technological cultures, and more specifically with what has been happening in Gujarat, a different language and indeed imagination are both called for. Despite the fact that the majority of the chapters in this part focus on Indian examples, we claim that the arguments developed in this part-just as in the other two parts-transcend the local contexts from which they originated. For example, the idea of the multiplicity of vulnerability is demonstrated both by Julia Quartz in chapter 2, "Agricultural Change in a South Indian Village: An Account of the Multiplicity of Vulnerable Livelihoods," on Indian farmers; and by Jessica Mesman in chapter 4, "Relocation of Vulnerability in Neonatal Intensive Care Medicine," on neonatology in a Dutch hospital.

Part I begins with the chapter by Quartz, who studies the livelihood vulnerabilities of farmers in India. Building on developments in the field of livelihood studies, she starts her analysis by applying a systemic perspective to vulnerability that stresses the interrelatedness of nature-related factors and social structural factors. To avoid an essentialist notion of vulnerability, she uses a diachronic perspective to analyze vulnerable livelihoods. Using this frame of analysis, she describes how the perception of who is to be considered as vulnerable changes diachronically between the
Green and Gene revolutions. Moreover, after applying a multiplied synchronous frame of analysis to policymakers, industries, and civil society groups, Quartz demonstrates how the meaning of vulnerable livelihood also differs synchronically. In this way, the chapter exemplifies not only the multiplicity of vulnerability, but also the fact that vulnerability is an issue of negotiation, and therefore also an issue of power structures.

This issue of power structures is also the central theme of chapter 3 , "Cultural Politics of Vulnerability: Historical-Ethnography of Dearth and Debt, and Farmers' Suicides in India," in which Esha Shah pays attention to (hi)stories about vulnerability and focuses on collective memories in India. However, whereas Quartz focuses on the modes of reasoning of policymakers, Shah studies the farmers. Similar to Quartz, Shah demonstrates how vulnerability is not so much shaped by a deficit of food and productivity, but by structural sociocultural inequalities, which in turn form the basis for a structurally unequal distribution of resources. Shah describes how liberal techno-institutions equate rural vulnerability with economic scarcity. In this rational economic approach, according to Shah, vulnerability is used as a political instrument to legitimize the introduction of new technological regimes like the Green Revolution and the Gene Revolution. Shah challenges this economic association between vulnerability and scarcity by employing the notion of "cultural politics." This cultural approach helps her to study the sociocultural connotations of scarcity in relation to farmers' suicides. Drawing on a detailed analysis of everyday conversations and historical narratives of famine, this chapter demonstrates how cultural imaginaries about scarcity and pauperization lie at the basis of vulnerability, and how cultural narratives play a crucial role in this matter. On the basis of these findings, she rejects the limited scope of the rational economic framework that refers to the dynamics of globalization and liberalization in order to explain farmers' suicides. Instead, the experience of agrarian vulnerability in India, Shah argues, is closely connected to a deeply ingrained cultural ideology of hierarchy and to Indian notions of the good life.

Shah's chapter underlines the multiplicity of vulnerability. In a similar vein, Jessica Mesman describes in chapter 4 how, when, and where these multiple vulnerabilities coexist, compete, and complicate practices. Whereas Quartz and Shah have stressed that vulnerability is an everyday experience of particular social groups, Mesman elaborates on the everydayness of vulnerability to underline that vulnerability is an emergent and relational property. To do so, her case study is situated in the hightech environment of an intensive care unit for newborns. By analyzing 
vulnerability on the level of the actors involved and their organizational arrangements, Mesman shows that vulnerability is the outcome of specific circumstances and perspectives. It turns out that there is not a single standard of what is considered as vulnerable, strong, or safe in this setting, but rather, standards depend on circumstance. In addition, the case studies in this chapter illustrate that vulnerabilities never occur alone, and that they coexist and sometimes even compete. This chapter also exemplifies the spatial and temporal relocation of vulnerability. Despite extensive safety measures, Mesman argues, vulnerability in most cases is not removed, but just moved around in space and time.

Mesman's chapter exemplifies the way that vulnerability is a form of potential distortion and disconnection of parts and processes. Likewise, in chapter 5, "Vulnerability and Development-Bhopal's Lasting Legacy," Sheila Jasanoff gives a clear example of the coproduction of technological and social order and disorder. Based on a detailed analysis of the aftermath of the Bhopal disaster in 1984 in India, she presents a critical discussion of global vulnerability. This "transnational vulnerability," she argues, arises when technological transfer ignores the epistemic, political, and cultural practices that are part of the technology. Jasanoff's concern is the situation that exists today, in which material technologies, such as chemical plants, and their related hazards flow freely around the globe while the respon sibilities and governance of these risks are still framed within national boundaries. What follows is a mismatch between transnational hazards and local national systems of risk governance. To demonstrate her argument, the chapter concentrates on the inadequacy of Indian law to deal with the aftermath of the Bhopal disaster, which was caused by a chemical plant, owned by a US company. Jasanoff asks why, according to the victims of Bhopal, "the case" is still not closed, despite the efforts of many lawyers.

As a social institution, law provides the entry to citizenship. However, this requires a legal system that fits the technological system that it is supposed to regulate. When law, as one of our fundamental mechanisms for reducing vulnerability, falls short, a collision of cultures of knowledge, experience, and justice follows. These frictions lay bare the multitude of hidden relations of dependence between actors of different kinds: between communities and industry, between governments and multinationals, and between untested and mature systems of liability law. In this way, Jasanoff shows how institutional absences of adequate knowledge, expertise, and justice can generate other forms of vulnerabilities. Like the chapters by Quartz and Shah, the chapter explicates the deeper structures of vulnerability and power that are induced by industrial globalization. It shows how vulnerability and citizenship are closely connected.
Visvanathan and Setelvad also show that the notion of vulnerability is closely tied to that of citizenship. In their chapter, citizenship is couched as a claim to normalcy, welfare, and well-being, while vulnerability is the breakdown of this expectation of normalcy. Studying vulnerability, they argue, should not only focus on susceptibility for disruption, but also should include the ability to recover. To examine people's ability to restore normalcy, they focus on the aftermath of the Gujarat riots in India in 2002. Visvanathan and Setelvad point to the analytical value of narratives: If one wants to understand vulnerability, one should pay attention to the changing nature of the stories about it. Normalcy, they argue, requires rituals of storytelling. If these narratives cannot be told due to collective denial or indifference, there is no closure. Without these narratives of truth and justice, there is no return to normalcy, and vulnerability continues. Without ignoring the existence and analytical strength of vulnerability as an objective, systemic, and scientific concept, Visvanathan and Setelvad prefer a phenomenological approach in which the subjective experience of the victims of the riots is at the center of attention. In giving victims a voice, the authors aim to provide an antidote against objectification, indifference, and ruthlessness with respect to experiences of victims of collective violence. In this way, survivors become subjects of history instead of mere objects of violence. While doing this, the role of technology is not denied; rather, it is taken into account on different levels: as symbol (the train to Pakistan), as materiality (the artifacts that were used in the killing), and as a metaphor (the technocratic style of managing society). In this way, the authors show how technologies and the technological culture that comes with it work together to create vulnerabilities through framing the dominant discourse.

All the chapters in this first part of the book address in their own way what it means to study vulnerability in technological cultures. Vulnerability, these chapters show, cannot be considered as one stable entity; instead, it is firmly embedded in the context in which it emerges. By opening up a diversity of domains ranging from legal, political, medical, and agrarian practices, part I demonstrates the multiplicity of vulnerability. It can, for example, be related to people's experiences, to technological equipment, or to societal institutions like law and democracy. Furthermore, vulnerability is explicated in many different forms, like narratives or conditions of bodies and machines. The broadness in scope of these chapters testifies to the wide range of issues and perspectives that we hope to address via the concept of vulnerability. 